\title{
PREVENTION OF CERVICAL CANCER WITH SEMINAR AND IVA TEST FOR PRODUCTIVE AGES WOMEN IN UNIVERSITAS NEGERI PADANG
}

\author{
Elsa Yuniarti, Rahmawati Darussyamsu, Moralita Chatri \\ JurusanBiologi FMIPA Universitas Negeri Padang, (0751)7057420/(0751)7058772, \\ *Email: rahmawati6786@gmail.com; Tel: 081363229286
}

Diterima 5 November 2019, Disetujui 21 Maret 2020, Dipublikasikan 31 Maret 2020

\begin{abstract}
Cervical cancer is one of the main problems of reproductive health in women in Indonesia. The results of a questionnaire of 100 women of productive age workers in UNP $80 \%$ had never done an IVA test and did not know about the IVA test for early detection of cervical cancer. Lack of knowledge and awareness of women workers at UNP to take preventive measures for early detection of cervical cancer, is carried out in prevention of cervical cancer with seminar and IVA test for productive ages women in Universitas Negeri Padang. Activities have been carried out in the rector's office, faculties and IVA test at the UNP polyclinic in collaboration with the Air Tawar Health Center, Padang City Health Office and the UNP Polyclinic. This activity has 3 stages namely seminar the importance of early detection of cervical cancer, IVA test and monitoring. Participants are women of childbearing age over the age of 18 who are married / widowed, not yet married but have had sexual intercourse at UNP. Seminar participants totaling 130 participants have exceeded the 30\% target. Monitoring activities are carried out with questionnaires to participants through a Google form sent to participant WhatsApp. The questionnaire contained aspects of knowledge and attitudes of participants towards early detection of cervical cancer. The results obtained $88.40 \%$ knowledge aspects (very good) and $84.16 \%$ attitude (good). But the participation for IVA test is still less than $10 \%$. With this activity increased knowledge and active role of women for preventive action with early detection of cervical cancer that aims to improve the quality of health and reduce the mortality rate of Indonesian women against cervical cancer.
\end{abstract}

Kata Kunci: kanker serviks, IVA test, wanita, UNP

This is an open access article distributed under the Creative Commons 4.0 Attribution License, which permits unrestricted use, distribution, and reproduction in any medium, provided the original work is properly cited. (C2017 by author and Universitas Negeri Padang.

\section{Pendahuluan}

Kanker serviks merupakan salah satu masalah utama kesehatan reproduksi pada perempuan di Indonesia. Menurut data International Agency for Research on Cancer (IARC) 2015, kanker leher rahim merupakan kanker terbesar ke-4 pada wanita diseluruh dunia. Prevalensi kejadian kanker leher rahim di seluruh dunia ialah sekitar 528.000 kasus baru kanker leher rahim pada tahun 2012 dengan 266.000 kematian penyebab kanker leher rahim di seluruh dunia. Di Indonesia kanker leher rahim merupakan kanker dengan prevalensi tertinggi yaitu sekitar 0,8\% atau sekitar 98.692 penderita kanker leher rahim di Indonesia [1][2].
Provinsi yang memiliki estimasi jumlah penderita kanker serviks terbesar adalah Provinsi Jawa Timur dengan estimasi 21.313 kasus. Sumatera Barat merupakan provinsi ke- 8 dengan estimasi jumlah kasus terbanyak di Indonesia yaitu sebesar 2.285 kasus [2]. Menurut data dari Riset Kesehatan Dasar (Riskesdas) tahun 2013 prevalensi kanker serviks di Sumatera Barat sebesar 170 per 100.000 penduduk. Menurut data dari Yayasan Kanker Indonesia (YKI) pada tahun 2007 Kota Padang merupakan penyumbang utama sebagai daerah dengan angka kejadian kanker serviks terbanyak dengan jumlah 107 kasus di provinsi Sumatera Barat [3]. 
Kanker serviks merupakan salah satu dari Penyakit Tidak Menular (PTM) yang menjadi perhatian pemerintah selain penyakit jantung, stroke, dan diabetes. Pencegahan dan pengendalian penyakit PTM telah diatur di dalam Undang-Undang no 36 tahun 2009 tentang Kesehatan dari Pasal 158 sampai dengan Pasal 161. Di dalam Pasal 161 secara tegas dikatakan bahwa manajemen pelayanan kesehatan baik berupa promotif, preventif, kuratif dan rehabilitatif dititik beratkan pada deteksi dini dan pengobatan penyakit tidak menular. Kanker serviks dapat diantisipasi dengan melakukan deteksi dini. Secara teori, tindakan mengikuti deteksi dini kanker serviks dengan tes IVA merupakan bagian dari perilaku yang mendukung kesehatan [4].

Hasil angket terhadap 100 wanita yakni ibu pekerja se-lingkungan Universitas Negeri Padang yang berusia produktif, mereka hampir menjawab $80 \%$ belum pernah melakukan pemeriksaan IVA dan tidak mengetahuai apa itu IVA dan hubungannya dengan kankers serviks. Hanya 20\% saja yang sekedar mengetahui kanker serviks tapi belum melakukan pemeriksaan IVA. Hal ini di karenakan kurangnya kesadaran dan pengetahuan akan penting melakukan scrinning kesehatan pribadi serta kendala waktu yang tidak memungkin untuk dapat pergi ke pelayanan kesehatan melakukan pemeriksaan IVA. Pemeriksaan Inspeksi Visual Asam Asetat (IVA) adalah salah satu metode skrining deteksi kanker dinding rahim yang sering dan mudah dilakukan [5].

Oleh sebab itu, kegiatan pengabdian ini bekerja sama dengan Puskesmas Air Tawar, Dinas Kesehatan Kota Padang dan Poliklinik Universitas Negeri Padang telah melaksanakan pengabdian kepada masyarakat dengan judul : “ Pencegahan Kankers Serviks melalui penyuluhan dan pemeriksaan IVA pada wanita usia produkstif se-Lingkungan Universitas Negeri Padang" dengan kegiatan ini menuntut agar wanita seLingkungan Universitas Negeri Padang dapat meningkatkan kualitas kesehatan dan menurunkan angka mortalitas wanita Indonesia dari penyakit kanker serviks.

\section{Solusi}

Langkah-langkah yang dilakukan untuk melaksanakan solusi yang ditawarkan dalam pencegahan Kankers Serviks pada wanita usia produkstif se-Lingkungan Universitas Negeri Padang dilakukan kegiatan peningkatan pengetahuan berupa penyuluhan tentang deteksi dini kankers serviks pada bulan Agustus 2019 di rektorat dan fakultas-fakultas di UNP yang target dihadiri oleh 100 peserta. Peserta adalah dosen, tenaga kependidikan dan tenaga kebersihan berjenis kelamin wanita berusia produktif lebih dari 18 tahun yang berstatus kawin/janda, belum kawin tapi sudah pernah melakukan hubungan seksual. Pemateri penyuluhan diberikan oleh dokter dari Puskesmas Air Tawar dan Dinas Kesehatan Kota Padang.

Monitoring kegiatan bersamaan dengan jangka waktu tunggu peserta untuk pemeriksaan IVA yakni dalam 2 bulan September dan Oktober 2019 setelah kegiatan peningkatan pengetahuan melalui penyuluhan. Pemeriksaan IVA dilakukan oleh dokter dan bidan dari Puskesmas Air Tawar yang dilakukan di Poliklinik UNP. Monitoring secara interpersonal terhadap peserta kegiatan juga dilakukan untuk evaluasi dan kemanfaatan kegiatan PKM ini terhadap peningkatan pengetahuan dan partisipasi peserta untuk deteksi dini kankers serviks.

\section{Hasil dan Diskusi}

Kegiatan pengabdian kepada masyarakat dengan judul Pencegahan Kankers Serviks melalui penyuluhan dan pemeriksaan IVA pada wanita usia produkstif se-Lingkungan Universitas Negeri Padang telah dilakukan pada bulan Agustus sampai akhir Oktober 2019. Pada bulan Agustus telah dilalukan penyuluhan deteksi dini kankers serviks bertempat di rektorat dan fakultas-fakultas di lingkungan UNP dihadiri 130 peserta ini melebihi target $30 \%$.

Dua bulan setelah kegiatan penyuluhan dilaksanakan, maka dilakukan monitoring dan evaluasi pada peserta kegiatan untuk mengetahui pengetahuan, sikap peserta terhadap pencegahan kankers serviks dan partisipasi peserta untuk melalukan pemeriksaan IVA di poliklinik. Kegiatan monitoring inter personal dilakukan 
dengan memberikan kuisioner bagi peserta kegiatan melalui google form yang dikirimkan ke WhatsApp peserta. Kuisioner yang diberikan memuat aspek pengetahuan dan sikap peserta terhadap deteksi dini kankers serviks.

Skor perolehan isian kuisioner dirataratakan dan dihitung persentasenya untuk melihat gambaran umum aspek-aspek yang dianalisis. Hasil analisis data ditampilkan pada Tabel 1.

Tabel 1. Deskripsi Rata-rata Persentase Pengetahuan dan Sikap peserta terhadap Deteksi Dini Kankers Serviks

\begin{tabular}{clc}
\hline No & \multicolumn{1}{c}{ Aspek } & $\begin{array}{c}\text { Rata-rata } \\
\text { Persentase (\%) }\end{array}$ \\
\hline 1. & Pengetahuan & 88,40 \\
2. & Sikap & 84,16
\end{tabular}

Berdasarkan data pada Tabel 1, terlihat bahwa setelah kegiatan pengabdian ini dilaksanakan, Peserta telah memiliki pengetahuan yang sangat baik tentang deteksi dini Kankers Serviks. Secara lebih terperinci, untuk hasil data tentang pengetahuan ditampilkan pada Tabel 2.

Tabel 2. Deskripsi Rata-rata Persentase Pengetahuan terhadap Deteksi Dini Kankers Serviks.

\begin{tabular}{|c|c|c|}
\hline No & Aspek & $\begin{array}{c}\text { Rata-rata } \\
\text { Persentase } \\
(\%)\end{array}$ \\
\hline 1. & Pengertian deteksi dini kanker & 85 \\
\hline 2. & Tujuan deteksi dini kanker & 88 \\
\hline 3. & $\begin{array}{l}\text { Cara melakukan deteksi dini kanker } \\
\text { leher rahim }\end{array}$ & 87 \\
\hline 4. & $\begin{array}{l}\text { Dampak keterlambatan dalam } \\
\text { mendeteksi kanker serviks }\end{array}$ & 95 \\
\hline 5. & Pengertian kanker serviks & 88 \\
\hline 6. & Penyebab kanker serviks & 80 \\
\hline 7. & Stadium kanker serviks & 98 \\
\hline 8. & Gejala-gejala kanker serviks & 89 \\
\hline 9. & Faktor resiko dari kanker serviks & 84 \\
\hline 10. & Pengertian test IVA & 81 \\
\hline 11. & $\begin{array}{l}\text { Waktu yang tepat untuk pemeriksaan } \\
\text { test IVA }\end{array}$ & 87 \\
\hline 12 & $\begin{array}{l}\text { Siapa yang harus menjalani } \\
\text { pemeriksaan IVA }\end{array}$ & 91 \\
\hline 13. & $\begin{array}{l}\text { Tempat pemeriksaan test IVA } \\
\text { Manfaat test IVA }\end{array}$ & 98 \\
\hline 14. & Manfaat test IVA & 87 \\
\hline 15 . & $\begin{array}{l}\text { Mendapatakn informasi tentang } \\
\text { deteksi dini kanker serviks }\end{array}$ & 88 \\
\hline \multicolumn{2}{|c|}{ Rata-rata } & 88,40 \\
\hline
\end{tabular}

Keseluruhan aspek pengetahuan memperoleh persentase $88,40 \%$. Hal ini menunjukkan bahwa peserta telah mengetahui dengan sangat baik pengetahuan tentang deteksi dini Kankers Serviks. Pengetahuan yang sangat baik dari peserta ini, merupakan fakta yang menunjukkan bahwa pengetahuan ibu tentang deteksi dini Kankers Serviks meningkat dengan diadakan kegiatan ini. Selain itu, kegiatan yang dilaksanakan difasilitasi oleh pakar di bidangnya, yakni dokter dan bidan dari Puskesmas Air Tawar dan Dinas Kesehatan Kota Padang. Dengan demikian, penyampaian materi dari pakar merupakan salah satu pendukung tercapainya target kegiatan ini.

Lebih lanjut, ditinjau dari aspek sikap peserta terhadap deteksi dini kankers serviks, diperoleh data bahwa sikap peserta berada pada kategori baik. Uraian secara rinci ditampilkan pada Tabel 3 .

Tabel 3. Deskripsi Rata-rata Persentase Sikap terhadap Deteksi Dini Kankers Serviks

\begin{tabular}{|c|c|c|}
\hline No & Aspek & $\begin{array}{l}\text { Persent } \\
\text { ase }(\%)\end{array}$ \\
\hline 1. & $\begin{array}{l}\text { Tes IVA penting sebagai deteksi dini } \\
\text { kanker serviks }\end{array}$ & 100 \\
\hline 2. & $\begin{array}{l}\text { Wanita berpikir terlihat sehat, bersih } \\
\text { dari perilaku seksual yang buruk tidak } \\
\text { perlu melakukan test IVA }\end{array}$ & 87 \\
\hline 3. & $\begin{array}{l}\text { Wanita berpikir yang belum aktif } \\
\text { secara seksual bisa melakukan test IVA }\end{array}$ & 84 \\
\hline 4. & $\begin{array}{l}\text { Wanita berpikir test IVA dilakukan } \\
\text { secara berkala maksimal lima tahun }\end{array}$ & 78 \\
\hline 5. & $\begin{array}{l}\text { Wanita berpikir manfaat dari } \\
\text { pemeriksaan test IVA dapat } \\
\text { mengetahui kelainan pra kanker pada } \\
\text { leher rahim secara dini, sehingga dapat } \\
\text { dicegah dan ditangani }\end{array}$ & 80 \\
\hline 6. & $\begin{array}{l}\text { Wanita berpikir test IVA dapat } \\
\text { dilakukan setelah ada gejala-gejala } \\
\text { kanker leher rahim }\end{array}$ & 83 \\
\hline 7. & $\begin{array}{l}\text { Wanita berpikir dalam kondisi } \\
\text { menstruasi tidak boleh melaksanakan } \\
\text { test IVA }\end{array}$ & 80 \\
\hline 8. & $\begin{array}{l}\text { Wanita bersikap jika suami melarang } \\
\text { untuk test IVA, wanita tetap } \\
\text { melakukan test IVA }\end{array}$ & 86 \\
\hline 9. & $\begin{array}{l}\text { Wanita bersikap tidak malu dan tetap } \\
\text { akan periksa terhadap test IVA yang } \\
\text { dilakukan pada bagian dalam } \\
\text { kewanitaan oleh bidan, perawat, } \\
\text { ataupun dokter }\end{array}$ & 84 \\
\hline 10. & $\begin{array}{l}\text { Wanita berpikir berganti-ganti } \\
\text { pasangan seksual dan merokok tidak }\end{array}$ & 79 \\
\hline
\end{tabular}




\begin{tabular}{|c|c|c|}
\hline No & Aspek & $\begin{array}{l}\text { Persent } \\
\text { ase }(\%)\end{array}$ \\
\hline & $\begin{array}{l}\text { perlu melakukan pemeriksaan IVA } \\
\text { secara rutin }\end{array}$ & \\
\hline 11. & $\begin{array}{l}\text { Wanita berpikir test IVA dapat } \\
\text { membantu mencegah kematian akibat } \\
\text { kanker leher rahim }\end{array}$ & 82 \\
\hline 12. & $\begin{array}{l}\text { Wanita berpikir kanker serviks hanya } \\
\text { terjadi pada wanita diatas usia } 50 \text { tahun }\end{array}$ & 87 \\
\hline \multicolumn{2}{|c|}{ Rata-rata } & 84,16 \\
\hline
\end{tabular}

Persentase sikap peserta memperoleh skor $84,16 \%$. Hal ini menunjukkan bahwa setelah penyuluhan dilaksanakan, peserta dapat menyikapi dan melakukan deteksi dini kankers serviks dengan baik. Melalui pencegahan dan deteksi kanker serviks sedini mungkin, semakin besar kesempatan disembuhkannya penyakit ini dan semakin besar kemungkinan untuk menekan angka kasus kanker serviks atau bahkan mengeradikasi (mengakhiri) ancaman ini dari kaum perempuan. Kanker serviks cenderung muncul pada perempuan berusia 35-55 tahun, namun dapat pula muncul pada perempuan dengan usia yang lebih muda. Mengingat usia ini adalah usia produktif, maka dapat dibayangkan apa yang terjadi dengan angkatan kerja perempuan yang menderitakan kerserviks. Waktu kerja mereka akan terganggu dengan adanya jadwal pemeriksaan dan terapi. Belum lagi banyaknya rupiah yang harus dikeluarkan untuk seluruh biaya itu [6].

Berbeda dengan aspek pengetahuan dan sikap dikategori sangat baik dan baik, partisipasi peserta untuk melakukan pemeriksaan IVA test mereka di Poliklinik UNP dalam jangka waktu 2 bulan setelah kegiatan belum sesuai dengan apa yang diharapkan hanya sebesar $10 \%$ dari peserta. Persentase yang diperoleh masih berada pada kategori rendah.

Menurut teori Notoatmodjo (2012) [7] bahwa sikap positif seseorang tidak otomatis terwujud dalam suatu tindakan nyata. Hal ini disebabkan oleh beberapa alasan yaitu sikap akan terwujud dalam suatu tindakan tergantung pada situasi saat itu. Sikap juga akan diikuti atau tidak oleh tindakan berdasarkan pada banyak atau sedikitnya pengalaman yang dimiliki seseorang. Sikap juga dipengaruhi oleh nilai-nilai yang menjadi pegangan setiap orang dalam masyarakat.
Sikap berbeda dengan perilaku, karena perilaku tidak selalu mencerminkan sikap seseorang. Seringkali terjadi bahwa seseorang memperlihatkan tindakan yang bertentangan dengan sikapnya. Sikap yang muncul dari dalam diri seseorang harus disertai dengan faktor lain seperti ketersediaan fasilitas, sikap tenaga kesehatan juga perilaku tenaga kesehatan itu sendiri.

Wanita Usia Subur (WUS) yang telah mendapatkan konseling IVA namun tidak melakukan pemeriksaan IVA dapat disebabkan oleh beberapa faktor seperti keengganan wanita untuk diperiksa karena malu, kerepotan, keraguan akan pentingnya pemeriksaan, kurangnya pengetahuan tentang pentingnya pemeriksaan, takut terhadap kenyataan hasil pemeriksaan yang akan dihadapi, ketakutan merasa sakit pada pemeriksaan, rasa segan diperiksa oleh dokter pria dan kurangnya dorongan keluarga terutama suami [8].

\section{Kesimpulan dan Saran}

Kegiatan pengabdian kepada masyarakat tentang Pencegahan Kankers Serviks melalui penyuluhan dan pemeriksaan IVA pada wanita usia produkstif se-Lingkungan Universitas Negeri Padang telah sukses dilaksanakan. Hal ini terlihat dari peningkatan pengetahuan dan sikap peserta yang berada pada kategori sangat baik dan baik. Namun, partisipasi peserta untuk melakukan pemeriksaan IVA masih belum sesuai target. Dengan demikian, diharapkan kedepannya UNP peran dari pimpinan dapat membuatkan suatu kebijakan agar wanita pekerja usia produktif di lingkungan UNP wajib melakukan pemeriksaan IVA sehingga dapat meningkatkan kualitas kesehatan dan menurunkan angka mortalitas wanita Indonesia dari penyakit kanker serviks.

\section{UcapanTerimaKasih}

Pada Puskesmas Air Tawar, Dinas Kesehatan Kota Padang dan Poliklinik Universitas Negeri Padang atas partisipasinya dan ucapan terimakasih yang tidak terhingga untuk mensukseskan kegiatan pengabdian ini. Pengabdian ini didanai oleh PNBP Universitas Negeri Padang pada skim PKM (Program 
Kemitraan Masyarakat) dengan nomor kontrak: 1383/UN35.13/PM/2019.

\section{DaftarPustaka}

[1] American Cancer Society. Cervical cancer prevention and early detection. 2014 [cited 2017 Aug 23]. Available from:

http://www.cancer.org/acs/groups/cid/do cuments/webcontent/003157-pdf.pdf
[6] Noorastuti, Piepit dan Anda Nurlaila. 2010. Kanker Serviks Renggut 20 Remaja per Hari [Internet]. Bersumber berdari: http://www.vivanews.com [Diakses tanggal 20 April 2009]

[7] Notoatmodjo, S. 2012. Promosi Kesehatan dan Ilmu Perilaku Kesehatan. Jakarta: Rineka Cipta.

[] Suratin dan Susanti. 2017. Hubungan Pengetahuan dan Sikap Ibu terhadap Deteksi Dini Kanker Serviks dengan Pemeriksaan IVA di Puskesmas Sekupang Tahun 2017. Jurnal Kedokteran. 07(03): 38 - 44.

[2] Kementerian Kesehatan RI. 2015. Profil Kesehatan Indonesia Tahun 2015. Jakarta: Kementerian Kesehatan RI.

[3] Dinas Kesehatan Kota Padang. 2017. Profil Keshatan Kota Padang Tahun 2017. Padang: Dinas Kesehatan Kota Padang.

[4] Fauza, M., Aprianti, dan Azrimaidaliza. 2019. Faktor yang Berhubungan dengan Deteksi Dini Kanker Serviks Metode IVA di Puskesmas Kota Padang. Jurnal Promosi Kesehatan Indonesia. 14(1): 68 - 80.

[5] http://binfar.depkes.go.id/dat/lama/13038879 05UU\%2036-2009\%20Kesehatan.pdf 